\title{
Editorial
}

\section{Industrial Biotechnology is Firing on All Cylinders}

Rebecca Coons

\section{Executive editor, Industrial Biotechnology}

I $\mathrm{n}$ the last issue of Industrial Biotechnology, I discussed the sustainability imperative driving unprecedented interest and innovation in industrial biotechnology. The ensuing two months have only underscored that the space is at an inflection point, with new breakthroughs, financings, and collaborations announced daily. The pace of press releases to my inbox in the last two months has frankly been overwhelming, but also reassuring; however big the coming challenges are, our innovation community is firing on all cylinders.

In this issue of Industrial Biotechnology, topics such as alternative proteins, waste valorization, plastics sustainability, adaptable biosystems, and market development are explored by executives and thought leaders. Research content covers diverse topics such as the cluster characteristics of biotechnology industries, biodegrading the synthetic polymer polyvinyl alcohol, and the optimization of carotenoid pigment extraction from Epicoccum nigrum fermented wheat bran. In the paper, The Cluster Characteristics of Biotechnology Industries and Their Effect on Regional Innovation Systems, Yum notes that biotechnology is a knowledge-driven sector and "among the most innovative and important economic drivers in our contemporary world." Kaur et al. shed light on how biotechnology can be harnessed to produce carotenoids-valued for antioxidant properties and a promising alternative for synthetic food colorings-more efficiently. Karuppiah and his colleagues demonstrate the efficacy of using a bacterium isolated from the Gulf of Mannar, in Tamil Nadu, India can be used to biodegrade a ubiquitous industrial pollutant.

We also excerpt a recent RethinkX report, "Rethinking Food and Agriculture 2020-2030: The Second Domestication of Plants and Animals, the Disruption of the Cow, and the Collapse of Industrial Livestock Farming." RethinkX is an independent think tank that analyzes and forecasts the speed and scale of technology-driven disruption and its implications across society. The authors believe we are "on the cusp of the deepest, fastest, most consequential disruption in food and agricultural production since the first domestication of plants and animals ten thousand years ago." By moving food production to the molecular level, "the number of nutrients we can produce is no longer constrained by the plant or animal kingdoms. While nature provides us with millions of unique proteins, for example, we consume just a fraction of these because they are too difficult or too expensive to extract from macro- organisms. In the new system of production, not only do these proteins become instantly accessible, but millions more that do not even exist today. Free to design molecules to any specification we desire, the only constraint will be the confines of the human imagination."

The report predicts production volumes of the US beef and dairy industries and their suppliers will decline by more than $50 \%$ by 2030 , and by nearly $90 \%$ by 2035 . The current industrialized, animal-agriculture system will be replaced with a Food-as-Software model, where foods are engineered by scientists at a molecular level and uploaded to databases that can be accessed by food designers anywhere in the world. Environmental benefits will be profound, with net greenhouse gas emissions from the sector falling by $45 \%$ by 2030 .

The financial community is also betting big on lab-grown proteins. In just the last few months, cash has been pouring into cultured meat startups. In the Netherlands, Mosa Meat has closed a Series B investment round of $\$ 85$ million. German labgrown fish startup Bluu Biosciences raised $€ 7$ million $(\$ 8.25$ million) to advance its cell-based salmon, trout, and carp, the most-consumed fish in China. In Israel, cultured meat start-up Future Meat Technologies has raised \$26.75 million and reduced the cost of its chicken breast to a remarkably low $\$ 7.50$ per quarter pound. In Australia, cultured meat startup Vow has raised \$6 million to expand its product pipeline of exotic meats, including kangaroo and alpaca. Israeli cultured meat firm MeatTech 3D has filed for a \$29-million initial public offering in the United States.

Singapore has been particularly keen on the cultured meat space. A small country with little land to grow food, the COVID-19 pandemic highlighted its food insecurity. The country recently became the first to give regulatory approval to a cultured meat product-Eat Just's chicken. Just weeks later, the company claimed the bragging rights to the first commercial sale of lab-grown meat. Good Food Institute Executive Director Bruce Friedrich told VegNews the move sets a precedent for other countries to "divorce meat production from industrial animal agriculture" and creates a "space race" for the future of food.

Even your pet can be greener with lab-grown proteins; Shannon Falconer and Joshua Errett, founders of Philadelphia's Because Animals, have demonstrated production of cultured mouse tissue without using fetal bovine serum. The startup hopes to launch animal free pet food in 2021 .

Pioneers are also eyeing the next-generation of alternative proteins. London designer Alice Turner has introduced a conceptual countertop bioreactor device that would, in the future, allow consumers to grow their own meat at home. Also in the 


\section{COONS}

United Kingdom, Moolec Science is looking to "molecular farming" by coaxing crops to create animal proteins. The company believes that by leveraging the scale of agriculture, it can create meat more effectively than emerging cultured meat processes. "Molecular farming is not yet a fully explored technology in the alternative protein space," Moolec CEO Gastón Paladini told The Spoon. "We do all the science up front from the lab to use genetic engineering to express animal cells." The company, a spinout of Bioceres, has already genetically modified safflower to produce chymosin, an animal protein found in the intestines of cattle and goats that can also be produced via fermentation. The company already sells the enzyme to cheesemakers.

Also in this issue, $I B$ was privileged to cover the recent Advanced Biosystems Workshop hosted by Ohio State University's College of Food, Agricultural, and Environmental Sciences. The timely event did a deep dive on the challenges facing the bioeconomy and brainstormed ways for technology, research, and the government to address them. Keynote speaker Doris de Guzman of Tecnon Orbichem noted that the bioeconomy has emerged as a "globally impactful, transformative force" on the supply side, and that other transformative forces-consumption changes and waste reduction - are driving the demand side. "Governments around the world are at historic crossroads, trying to manage short-term pressures and medium- and long-term uncertainties, especially brought on by the climate change crisis and now accelerated by the global COVID-19 pandemic," she adds.

Ajay Shah, associate professor in the Department of Food, Agricultural, and Biological Engineering and Program for Bioproducts and the Environment at Ohio State University, discussed strategies to enable biobased systems. Genetics and biotechnology applied to biomass development, biomass breakdown, and biofuel and bioproduct synthesis can enable more efficient production of biofuels and bioproducts, he says. Waste valorization through composting, anaerobic digestion, and thermochemical treatments can help make the bioeconomy more resilient. Adaptable biobased industries capable of responding to changing circumstances are required for surviving uncertainty and volatility, he adds.

Also in the issue, we interview two key players in the bioeconomy: John Melo, president and CEO of Amyris (Emeryville, CA) and John Bissell, co-founder and co-president of Origin Materials (West Sacramento, CA). Both are bullish on the prospects for the bioeconomy, buoyed by unprecedented consumer interest, technology breakthroughs, and brand sustainability commitments. "The breakthrough has really been the maturity of the technology," Melo tells $I B$. "We are now able to move a molecule from target to scale in a year or less. For a partner, that is really critical-you make your investment and then you can confidently plan a development cycle around that molecule. That definitely was not possible ten years ago. Now, the model is robust."

I would like to take this opportunity to thank our readers for their tireless efforts to help create a more sustainable world. We at $I B$ will continue our commitment to keeping you abreast of the latest developments and trends, but I would also encourage you to get in touch with me (rcoons@ liebertpub.com; 1508 951$3505)$ if you have an innovation story to tell. As the pace of innovation continues to accelerate, we will need more collaboration across geographies and industries to meet our sustainable and human development goals. 